\title{
PERFORMANCE ARTE: MULTIDISCIPLINARIDADE COLABORATIVA COMO EXPERIÊNCIA SENSÍVEL
}

\section{Gisela Reis Biancalana}

Universidade Federal de Santa Maria

\section{RESUMO}

Este artigo reflete sobre um trabalho de criação em Performance Arte que amalgamou as artes visuais, o teatro e a dança em uma concepção interartística envolvendo, ainda, a pesquisa de campo antropológica em sua perspectiva transdisciplinar. A investigação esteve focada no processo criador colaborativo de nove performances que compuseram uma ExposiAção. A experiência individual e, simultaneamente, coletivizada dos artistas contribuiu significativamente para a definição das escoIhas éticas, estéticas e políticas que atravessaram o processo como um todo. A pesquisa leva em consideração que a tentativa de conceituar a performance é uma tarefa árdua devido à amplitude dos desdobramentos do termo, sobretudo nos universos artísticos multidisciplinares. Por outro lado, ela coloca-se como um espaço-tempo diverso e plural de corpos-arte, situando-se como presença recorrente na arte contemporânea. A presente investigação busca, ainda, fazer o recorte do entendimento de performance como momento de uma experiência sensível.

Palavras-chave: Performance. Criação. Pesquisa de Campo. Processo Colaborativo. Experiência 
s complexos e diversos contextos do mundo contemporâneo se expandem no espaço-tempo e deslizam por redes de manifestações humanas oriundas de perspectivas diversas. O século XX propôs rupturas significativas com visões de mundo paradigmáticas. Seria impossível pontuar os incontáveis pensadores que, de certa forma, alavancaram as mudanças paradigmáticas do século XX. ${ }^{1}$

Os antigos e hegemônicos modos de pensar borbulham e transbordam para outras perspectivas do mundo em todos os campos do saber humano desde as ciências, as filosofias até as artes. Merecem destaque os efeitos do descontentamento com as dimensões humanas sufocadas pela razão. A expressiva valorização da razão, reforçada pelo cogito, ou pela célebre frase do francês Renè Descartes, "penso, logo existo", é apenas um dos detonadores de algumas destas reflexões.

Os atuais percursos crítico-reflexivos operantes no contemporâneo buscam revolver modos definitivos de ser-estar, pensar, agir e sentir humanos para outros modos mais transitórios, expandidos, incertos, sensíveis.Aqui, o prefixo "pós" se multiplica em pós-moderno, pós-humano, pós-dramático, entre outros. A arte contemporânea emerge deste pós, e não poderia ser diferente.

As vanguardas europeias do início do século XX já gritavam por rupturas que repercutiram em proposições de saberes diversos nas décadas seguintes. ${ }^{2}$ Atualmente, estes saberes dividem espaço com outros de diferentes origens advindos de lugares e tempos também diversos. Oriente, Ocidente, norte, sul, passado, presente - e até mesmo perspectivas de futuro - se misturam formando férteis caldos de conhecimento pluralizados e detonadores de possibilidades múltiplas do fazer. Além da expansão espaço-temporal, há, ainda, uma imensidão multifacetada de diversidades sociais, econômicas e culturais se reinventando cotidianamente.

Os modos tradicionais de conceber arte que resguardam suas convenções históricas convivem com os modos recorrentes de operar atualmente, repercutindo em muitas transformações. Estas transformações atuam sobre o tempo em seus desdobramentos e dimensões; o espaço e seus multifacetados aparecimentos; o corpo em suas múltiplas possibilidades de performar nas artes, entre outras, bem como as incontáveis formas de conceber a arte desprendida do enquadramento histórico em ismos. Sustentada por encaminhamentos elaborados e apoiados em escolhas técnico-expressivas e formais coerentes com cada proposição emergente,

\footnotetext{
1 A teoria da relatividade einsteiniana desmontou a ideia imperante sobre os conceitos de espaço e, especialmente, de tempo. Seus pressupostos abalaram a crença em dimensões absolutas e trouxeram à tona o pensamento relativizado. $O$ indeterminismo enquanto concepção filosófica que prega a não causalidade e a não linearidade das coisas também contribuiu para uma perspectiva ramificada do mundo. A teoria quântica, ao discutir os fenômenos da matéria, muda sua própria concepção de si entendendo-se como probabilidade não mais como algo definido e previsível. Freud, com suas ideias sobre o inconsciente, e Jung, sobre o inconsciente coletivo, também contribuíram significativamente para a valorização de aspectos do ser que vão para além do indivíduo e da razão consciente.

${ }^{2}$ Vale salientar aqui que, mesmo reconhecendo que as vanguardas se referem a um tipo de arte herdeiro de uma organização sociocultural ocidental europeia, branca, colonizadora e dominante, não se pode esquecer que as Américas, por sua vez, são também descendentes deste fazer por tanto tempo hegemônico e comprometido com a razão moderna.
} 
a arte contemporânea ainda se reorganiza não só afetada, mas também afetando o intenso, dinâmico e sintomático desenvolvimento tecnológico que impõe as simultaneidades e virtualidades próprias do mundo atual.

Esta revolução atravessa os corpos contemporâneos se reconfigurando em estados múltiplos e desestabilizadores dos seres humanos e, aqui, dos artistas contemporâneos, entre os quais estão os criadores desta investigação. Entre as buscas destes artistas insere-se o objetivo do artigo calcado no processo criador colaborativo de nove performances que compuseram uma ExposiAção. Esta ExposiAção foi uma exposição de nove corpos em performance realizando ações repetidas ao longo das duas horas em que estiveram expostos a cada presentação. ${ }^{3}$ As ações performativas agregaram atores, bailarinos e artistas visuais em dois eventos, o primeiro no ano de 2016 e o segundo em 2017. Este trabalho de criação em arte consistiu em uma concepção interartística e, ainda, envolveu a pesquisa de campo antropológica que respaldou sua perspectiva transdisciplinar. A experiência individual e, simultaneamente, coletivizada dos artistas contribuiu significativamente para a definição das escolhas éticas, estéticas e políticas do trabalho, reverberando a experiência sensível dos artistas.

Para refletir sobre o trabalho proposto, este texto assentou sobre a arte contemporânea, antes de tudo, apenas para situar a Arte da Performance enquanto manifestação inerente a este contexto multidisciplinar. Subsequentemente, atravessa a Antropologia e a pesquisa de campo como experiência no intuito de clarificar o trânsito transdisciplinar como opção investigativa. Na sequência, percorre o pulsante conceito de processo colaborativo aportado na elaboração da ExposiAção para chegar a algumas considerações momentâneas que pairam sobre a perspectiva adotada.

\section{A Arte da Performance - arte múltipla}

A presente reflexão leva em consideração que a tentativa de conceituar a performance é uma tarefa árdua devido à amplitude dos desdobramentos do termo, sobretudo nos universos artísticos contemporâneos. $O$ termo também deve sua amplitude como sinônimo de desempenho, especialmente em ações bem-sucedidas. Em universos acadêmicos, muitas vezes ela é estudada a partir do campo denominado Estudos da Performance, dedicando-se, segundo Schechner (2003), ao momento em que se manifestam um ou mais corpos para apreciação de outros com as mais diversas formas e funções. Porém, em qualquer destes contextos trata-se de um momento no qual uma ação se materializa, tendo sido concebida para ser fugazmente compartilhada. Os Estudos da Performance remetem-se a eventos bem-definidos e delimitados, marcados por um

\footnotetext{
3 Em alguns dicionários da Língua Portuguesa, aparece como sinônimo de apresentação, mas neste texto ele remete ao estar presente enquanto corpo performativo em oposição à ideia de representação de outra coisa que não ele mesmo.
} 
contexto, por uma convenção, pelo seu uso e/ou pela tradição, sempre tendo o corpo agente como primeira referência. As performatividades "afirmam identidades, curvam o tempo, remodelam e adornam os corpos, contam histórias" (Schechner, 2003, p. 27). Por outro lado, não se pode esquecer que as performances são parte constitutiva de um processo amplo formativo, sociocultural e/ou criativo que a antecede.

Neste trabalho, o termo performance remete a mais um de seus desdobramentos, ou seja, refere-se a uma manifestação artística que recebeu esta denominação por volta dos anos de 1960-70, oriunda das investidas dos vanguardistas do início do século XX e de expoentes das artes visuais, da dança e do teatro ao longo das décadas seguintes. Assim, a Performance Arte

[...] começa a receber este nome por volta dos anos sessenta nos Estados Unidos da América. Seu pressuposto básico é o entendimento o corpo como obra de arte. Seu caráter experimental emerge de diversas outras manifestações artísticas anteriores, desde as Vanguardas do início do século XX, mas foi aceita como meio de expressão artística por volta da década de setenta. (Goldberg, 2002, p. 7).

Entre suas proposições estão o não enquadramento estético que opera na inexorável diluição de fronteiras entre artes. A incorporação do acaso também se faz recorrente com a abertura para o improviso em graus inusitados até então. A interlocução entre arte e público aparece com um viés de certo modo deselitizante ao promover o acesso destituindo o museu e o teatro como únicos lugares da obra. Há, ainda, em alguns trabalhos, a interação com o público, que passa a ser instigado à participação. $O$ apelo a outros sentidos, para além da visualidade, também aparece com frequência nestas obras. Além disso, o cunho transgressor deste tipo de arte é intenso, pois suas obras comumente carregam um tom subversivo formatado pela sua construção social artisticamente simulada. Segundo Taylor, a

[...] performance [...], por ser uma construção social, aponta para artificialidade, uma simulação ou "encenação", antítese do "real" e "verdadeiro". As suspeitas remetem as mesmas línguas de origem: "arte" está linguisticamente ligada a ARTIFíCIO. (Taylor, 2012, p. 33, grifo do autor).

A arte contemporânea é constituinte deste mundo, bem como o constitui, e a Performance Arte é um dos modos de manifestar-se do ser humano neste contexto. Portanto, neste universo aparentemente conturbado pelo abalo de paradigmas estabilizadores, o artista contemporâneo emerge com sua produção questionadora de si, sobretudo perscrutando um estado desestabilizador do seu campo de conhecimento lançando-se ao múltiplo. A palavra multidisciplinar vem, então, deste contexto claramente instigador. $O$ tempo é reinventado em dimensões pluralizadas, os espaços instituídos são reavaliados multiplicando possibilidades jamais cogitadas; enfim, são diversos os desdobramentos deste contexto expandido. 
Assim, o próprio artista como corpo-arte ${ }^{4}$ repensa a si mesmo e se apresenta como obra.A performance surge deste universo instigador com a hibridação das linguagens em comunhão com o público, especialmente, pressupondo esta precipitante presença do corpo do artista que emerge como obra, ou seja, torna-se a própria obra. Nas palavras de Battcock (apud Cohen, 2002, p.76), "em performance a figura do artista é [...] a própria arte". Peggy Phelan, por sua vez, ao refletir sobre a ontologia da performance, afirma que a

[...] única vida da performance dá-se no presente. A performance não pode ser guardada, registrada, documentada ou participar de qualquer outro modo de circulação de representações; no exacto momento em que o faz ela torna-se imediatamente numa coisa diferente da performance. É na medida em que a performance tenta entrar na economia da reprodução que ela trai e diminui a promessa da sua própria ontologia. O ser performance, tal como a ontologia da subjetividade que aqui é proposta, atinge-se pela via da desaparição. (Phelan,1997, p. 171).

Mesmo considerando a lógica coerente da autora, é imprescindível lembrar de que, no século XXI, a implacável convivência com as virtualidades tornou-se quase inseparável das formas de organização da vida humana. Termos como videoperformance, fotoperformance, reperformance multiplicam-se. De certo modo, Benjamin (1955) já aludia a este vertiginoso panorama em meados do século XX, quando mobilizou o pensamento sobre a crescente reprodutibilidade técnica das obras de arte. Na esteira deste pensamento, Melim tenta fazer uma abordagem que, ela mesma, chama de mais distendida sobre o conceito de performance nas artes visuais. Para a autora, essa noção surge com

[...] uma variante de procedimentos, reexaminada por meio de elementos performativos presentes na ordem construtiva de muitos trabalhos apresentados na forma de vídeos, instalações, desenhos, filmes, textos, fotografias, esculturas e pinturas. (Melim, 2008, p. 9).

As inquietações exploradas neste trabalho encontraram na Performance Arte os lugares expandidos da cena contemporânea. Como dito anteriormente, as produções cênica e visual contemporâneas constituem e são constituintes dos modos de ser, estar, sentir e pensar no mundo pós-moderno, pós-humano, pós-dramático, entre outros. Atualmente, a performatividade transborda para saberes que são dinamicamente reelaborados sobre plataformas transdisciplinares, híbridas, com fronteiras rarefeitas, constantemente se desestabilizando pelos percursos imprevisíveis dos acasos. Aqui, a performance emergiu como arte contemporânea na qual o corpo é a própria arte, e não seu instrumento, suporte ou condutor, seja ele presencial ou virtual.

\footnotetext{
4 O corpo-arte é aquele "que se presentifica nas performances, em qualquer forma cênica" (Biancalana,
} 2014, p. 167). 
A recorrente discussão sobre o pertencimento da Performance Arte parece ser, então, uma visão empobrecedora, pois suas primeiras manifestações já buscavam escapar dos enquadramentos estéticos vigentes e hegemônicos de sua época. Segundo Melim (2008, p. 10), desde "as vanguardas europeias, já se esboçavam ações performáticas que objetivavam rupturas". Entre as batalhas das vanguardas do início do século XX, desponta a ruptura com fronteiras enrijecidas das linguagens artísticas e seus pressupostos epistemológicos ainda dogmáticos. Sendo assim, a perspectiva transdisciplinar deste trabalho é interartística e convoca a Antropologia ao adotar a pesquisa de campo como um dos dispositivos disparadores de sua prática.

\section{Pesquisa de campo - perspectiva transdisciplinar}

Não foram apenas as artes que promoveram rupturas estrondosas com os modos de fazer vigentes. As reformulações paradigmáticas que germinaram em todos os campos de saberes obstruíram fronteiras limítrofes ora intactas. Desse modo, os modos de fazer pesquisa também revolveram os direcionamentos investigativos tradicionais que eram amparados por métodos científicos norteadores e ordenadores de suas práticas. Muitos métodos de pesquisa anteriores ao século XX tinham uma postura contornada pelo seu campo epistemológico e adotavam um modus operandi linear e causal.

Esta nova paisagem desencadeia a travessia para rastrear e acolher a diversidade. Neste contexto, esta investigação artística performativa não se utilizou de um método científico predeterminado. Sua proposta se apropriou de alguns encaminhamentos metodológicos que puderam proporcionar a elaboração de um procedimento que, por sua vez, admitiu certa flexibilidade durante o trabalho. A principal abordagem deste procedimento metodológico é o diálogo estabelecido com a Antropologia na apropriação da pesquisa de campo como momento instigador do fazer. Torna-se fundamental apontar a pesquisa de campo como momento instigador, e não como espaço-tempo fomentador de interpretações etnográficas. Os elementos que surgiram das relações estabelecidas em pesquisa de campo constituem as performances elaboradas para a ExposiAção.

A escolha de propor as idas a campo se deu por visualizar nelas um modo de aproximação com o universo pesquisado e de adentrar em suas experiências e visões sobre si no mundo. De acordo com Laplantine, a pesquisa de campo "não consiste apenas em coletar, através de um método estritamente indutivo uma grande quantidade de informações, mas em impregnar-se dos temas obsessionais de uma sociedade, de seus ideais, de suas angústias" (Laplantine, 1996, p.149). Ao importar estas vivências para o processo criador, o objetivo não foi discursar por estas pessoas investigadas, mas conversar com elas. As vivências se misturaram e em momento algum foram separadas das intenções pessoais dos pesquisadores. Ao contrário, elas foram assumidas, amalgamadas e constituintes da obra. Não há neutralidade ou imparcialidade nesta proposta de criação artística e acadêmica. 
A experiência em campo se relaciona diretamente com as próprias origens do termo performance. A palavra performance deriva do francês antigo parfournir, que significa "completar ou realizar inteiramente"; assim, ela indica o momento da expressão/comunicação que completa uma experiência, é o último dos momentos que constituem a estrutura processual da experiência vivida. Portanto, ela é parte da expressão da experiência, como afirma Turner (apud Dawsey, 2005, p. 163-164). Ou seja, a obra tem o espaço-tempo de campo como parte constituinte de seu momento performativo.

Ao abordar a palavra experiência, buscou-se, ainda, enfocá-la de acordo com os argumentos de Bondía (2002, p.25) para iluminar o entendimento sobre este termo que tem sido explorado, muitas vezes, de maneira banal, quantitativa e utilitária. A etimologia da palavra experiência deriva do latim experiri, que significa provar no sentido de experimentar, sendo que o radical periri também faz parte de periculum, que, por sua vez, significa perigo. O escrutínio da palavra em sua origem indo-europeia per permite encontrar a ideia de travessia, que significa tentar, aventurar-se, correr riscos. Entre as raízes gregas encontra-se perao, que significa passar por, e peras, que significa limite. $O$ autor ainda atenta para o prefixo ex, que condensa os significados de exterior, estrangeiro, exílio, estranho e existência.

O mundo contemporâneo, com sua rapidez crônica, sua assombrosa ânsia de produtividade e seu forte traço preventivo, características que se proliferam via informação, esvazia a experiência, tornando-a mais rara a cada dia. A experiência, para Bondía (2002), é explorada a partir de um viés existencial, associando-a à produção de sentido em oposição aos ideais da informação/opinião com os quais ela tem sido aproximada. Desta forma, sendo algo que acontece em alguém, não pode ser apenas algo que passa por alguém sem produzir sentido. A performance enquanto produção de sentido implica abertura, receptividade e exposição, realizada via experimentação, travessia, risco, a partir de algo que toca profundamente.

Para Bondía (2002, p.22), a experiência deve ser separada da informação. O saber da experiência é diferente do saber sobre os fatos referentes às coisas. A informação dispara uma leitura que produz o conhecimento racional. A leitura sensível, por sua vez, não é racional e pode propor a experiência. Este percurso da experiência vai ao encontro de uma das características da performance. Segundo Cohen (2002, p.66), ela propõe

[...] a eliminação de um discurso mais racional e a utilização mais elaborada de signos [que] fazem com que o espetáculo de performance tenha uma leitura que é antes de tudo uma leitura emocional. Muitas vezes o espectador não "entende" (porque a emissão é cifrada), mas "sente" o que está acontecendo.

Portanto, a performance pode propor uma leitura sensível e/ou racional. Muitas vezes, não se trata apenas de propagar seus possíveis códigos para apreciação. Os códigos por si só podem não atingir o público, mas podem permitir uma leitura racional de sua informação. Há performances que se preocupam prioritariamente com esse caráter da 
emissão cifrada, e não com a leitura refinada dos sentidos. São formas distintas e não excludentes da Performance Arte. A experiência para além da dimensão racional é provocadora e transgressora deste mundo ainda fortemente guiado pela razão.

Marina Abramovic, uma das principais expoentes contemporâneas da arte da performance, é uma insistente articuladora das fricções de experiências que impiedosamente colocam os estéreis saberes acomodados na berlinda. Esta artista tem proposto, recorrentemente, experiências impactantes ao seu público. Suas obras exigem muito de seu preparo psicofísico para conseguir o objetivo desse contato-experiência entre performer e público. Entre suas últimas peças está The Artist is Present, em que ela se propõe a ficar sentada no Museum of Modern Art durante oito horas por dia, seis dias por semana, em um período de três meses. Sua ação consiste, apenas, em esperar que pessoas se sentem à sua frente para olhá-la. Segundo a própria performer, tal proposta exige um preparo intenso de si.

Porém, além da simplicidade, sempre estou envolvida com esforço, e meu trabaIho exige uma quantidade imensa de preparo. Isso se aplica, em especial, a The Artist is Present (A artista está presente) - uma das peças mais difíceis que criei. [...] Quando terminei The Artist is Present, sentia total exaustão mental e física, como nunca havia sentido antes. E também toda a minha visão de mundo, tudo o que parecia importante antes, minha vida diária, as coisas das quais gostava ou não, tudo virou de ponta-cabeça. (LUCIANA BRITO GALERIA, 2010, p.17).

Desta fala de Marina pode-se deter um aspecto que se aproxima com o modus operandi desta pesquisa. A preparação da artista é entendida como performance-experiência, modificadora do ser, pois a obra atinge o próprio artista. Para Bondía (2002, p. 19), este sujeito da experiência

[...] não é o sujeito da informação, da opinião, do trabalho, que não é o sujeito do saber, do julgar, do fazer, do poder, do querer. Se escutamos em espanhol, nessa língua em que a experiência é "o que nos passa", o sujeito da experiência seria algo como um território de passagem, algo como uma superfície sensível que aquilo que acontece afeta de algum modo, produz alguns afetos, inscreve algumas marcas, deixa alguns vestígios, alguns efeitos.

Afinal, aqui, o corpo-arte se apresenta como um território de passagem no qual a obra interfere instantaneamente. A obra existe no momento do contato com o público, precipitando uma interlocução entre o(s) artista(s) e a obra. Didi-Huberman (1997) fala que não se vê somente aquilo que é visível materialmente na forma da obra. No momento em que se olha para a obra, algo pode tocar profundamente se a conexão instalar um fluxo fecundo de trocas. Os efeitos do contato com as obras de arte passam pelo campo visual, mas também por outros campos do sensível. Isto pode acontecer a partir das referências de vida dos envolvidos no contato. A obra que 
não é um objeto, mas é corpo-arte que também olha com todas as suas referências, compondo interferências múltiplas e dinâmicas. A abordagem do autor supracitado, embora focada em objetos artísticos, pode ser pensada na performatividade, pois o corpo do performer é a obra. Em suma, o autor propõe que é preciso fechar os olhos para ver, e isso pertence ao campo da experiência, uma vez que o

[...] ato de dar a ver não é o ato de dar evidências visíveis a pares de olhos que se apoderam unilateralmente do "dom visual" para se satisfazer unilateralmente com ele. Dar a ver é sempre inquietar o ver, em seu ato, em seu sujeito. Ver é sempre uma operação de sujeito, portanto uma operação fendida, inquieta, agitada, aberta. (Didi-Huberman, 1998, p. 77).

Deste ponto de vista, olhar uma obra também se aproxima da experiência apontada por Bondía, especialmente em obras como as de Abramovic, que, por si só, propõem uma experiência compartilhada. Quando a artista cita tais termos, ela pode referir-se, em primeira instância, à transformação de si e ao tipo de expressão-comunicação que ela busca com seu público, uma "transmissão direta de energia entre o artista e o público" (Quillici, 2008, p. 2). A busca por essa conexão se relaciona com o trabalho sobre si desde a concepção do trabalho criador. A expressão-comunicação que Abramovic busca não pertence apenas ao campo da racionalidade e da informação, mas da experiência. A transmissão de energia citada por Quillici ocorre para além do plano da informação ou da mera decodificação. Ela busca tocar os sentidos pela via dos códigos propostos. Sentar-se em uma cadeira no The Museum of Modern Art foi uma parte de seu trabalho. Antes dessa simples ação, e mesmo de cada performance da artista, houve um trabalho que antecedeu a obra. Esse preparo faz parte da vida e da obra da artista, entrelaçando-as para além do visível e do racional. Cada artista escolhe, em sua vida e arte, as experiências que traz consigo, e acolhe as que possam ser provocadoras de seu fazer performativo.

Nesta pesquisa, o local da pesquisa de campo já foi escolhido a partir de inquietações pessoais de cada artista e multiplicou suas intensidades, desejos e texturas no contato com o campo. Este trânsito alucinado das inquietações tomando corpo em pesquisa de campo se proliferam ainda mais em laboratório de criação colaborativa das performances que compuseram a ExposiAção.

\section{A ExposiAção e a colaboratividade}

A ExposiAção foi um trabalho realizado por artistas de um grupo de pesquisas que investiga relações entre performatividade artística e elementos culturais. Assim, ao considerar o contexto pluralizado, multifacetado, exposto ao longo do texto, foi necessário, ainda, cartografar a redefinição de relações entre os membros dos grupos de artistas no contemporâneo para estabelecer as posturas criadoras no próprio grupo. Esta redefinição vai delineando nomenclaturas também diversas, tais como "coletivos" 
e "colaborativos", termos mais recorrentes no panorama atual. O uso indiscriminado destes termos não tem sustentado suas propostas, e esta discussão não é exclusiva das artes. Portanto, buscou-se abarcar apenas algumas questões que gravitam em torno do surgimento destes termos, a partir de meados do século XX, a fim de iluminar os modos de operar dos grupos e seus meios de entender a criação com ressonância nas concepções expandidas da arte contemporânea.

Florian Schneider (2007) é um dos autores que têm pensado sobre os trabalhos desenvolvidos por diversos grupos na contemporaneidade. O autor, professor da Universidade da Noruega, é também cineasta, ativista e escritor. Porém, o que interessa são seus apontamentos objetivos e sua abordagem dos trabalhos conjuntos, que estão relacionados ao mundo atual. Se, por um lado, o discurso deste autor não está direcionado para a produção artística especificamente, por outro lado, seus argumentos auxiliam a pensar nos trabalhos conjuntos que vêm se intensificando nos universos artísticos contemporâneos, semelhante a uma malha tecida por fios diversos e mutantes.

Diante da exposição reflexiva do autor, ele se debruça, em especial, sobre o termo "colaborativo"". Deste modo, colaborativo não é simplesmente trabalhar em conjunto, mas, sim, formar uma rede de abordagens e esforços interconectados. Esta rede busca a não neutralização do indivíduo diante de algum tipo de ideologia comunitária, como costumava acontecer nos coletivos surgidos em meados do século XX. Nos coletivos havia uma espécie de subordinação dos participantes a uma identidade comum. Os indivíduos precisavam se amalgamar, perdendo a própria identidade em nome de uma ideologia aglutinante. Nos coletivos prevalece o homogêneo, o unificado, o similar, a conformidade, o consenso. Nos colaborativos há uma espécie de coexistência que visa respeitar os encaminhamentos individuais.

Atualmente, as reflexões sobre processos colaborativos nas artes ainda se encontram num nível preliminar, eclético e incompleto de compressão e definição, edificando um momento que urge por discussão, mesmo que elas contribuam para gerar ainda mais (in)compreensão e (in)definição. Desta maneira, a palavra colaboração tem sido dirigida por uma realidade complexa que se situa além da noção romântica de comunidade. É uma relação paradoxal entre coprodutores que se afetam uns aos outros.

Os colaboradores não estão questionando uma autoridade, muitas vezes necessária, nem pretendendo uma utópica igualdade. Pelo contrário, valores como lideranças e diversidade de experiências são compreendidos, pois a igualdade seria padronizante. Aqui, evita-se a arrogância do poder absoluto, incondicional e, muitas vezes, esvaziado. Esta prerrogativa se aproxima das perspectivas de ser no mundo contemporâneo que absorvem a diversidade, a instabilidade, o risco, o erro, a pluralidade, as múltiplas dimensionalidades do espaço e do tempo. A colaboração não busca um sistema de trocas de posses, mas de fluxo, nos quais as posições estáticas de manutenção do poder são afastadas. 
Nestes contextos, muitas vezes, nada se produz sem causar o menor alarme. Pelo contrário, entende-se a vacuidade como possível força propulsora da criação. Este modo de funcionar promove um movimento capaz de gerar a chance de um acesso imprevisto. $O$ desejo de cruzar as fronteiras familiares da experiência, das habilidades e dos próprios recursos intelectuais se redireciona no sentido de adentrar em territórios amplificados de dimensões não exatas. As habilidades emergem do contato e da relação com outros. Ao trespassar os limites estagnados de operações previsíveis, os envolvidos podem se encontrar em uma inesperada e múltipla rede de pontos incertos de contato que provocam deslizamentos, cruzamentos e trocas.

A colaboração, desta forma, implica a aceitação do instável. Ela realiza permutas de saberes, movimentando o conhecimento. O colaborativo desenvolve relações diferenciadas entre indivíduos heterogêneos definidos como singularidades. Os processos colaborativos, por serem descontínuos e imprevisíveis, permanecem mesmo quando os objetivos gerais do grupo assumem uma direção particular. A pura racionalidade absorve a relacionalidade que descompõe e recompõe informações e/ou para uso temporário em inesperadas dinâmicas.

Os processos colaborativos permitem a singularização dos participantes, especialmente ao recusar as antigas posturas hierárquicas autoritárias e a diluição das singularidades. $\mathrm{O}$ trabalho colaborativo preza pela não conformidade ideológica e aponta para um horizonte de possibilidades que não significam necessariamente cumplicidade. Os indivíduos podem realizar aproximações e distanciamentos sem comunhão ou unificação. Rusham (2015) propõe um modelo de colaboração que ela chama de pós-consensual, na qual os participantes da configuração colaborativa podem garantir certa autonomia, preservando sua singularidade no grupo.

O processo criador adotado para a ExposiAção foi desenvolvido considerando esta complexidade do mundo contemporâneo. O procedimento surgiu como um percurso integrador das experiências singulares. As escolhas individuais abordaram questões políticas emergentes no intrincado manancial de paisagens socioculturais latentes e instigadoras da prática performativa em andamento. Os elementos impulsionadores da proposta estiveram ancorados na experiência de vida atrelada à experiência advinda da pesquisa de campo, em especial, nos obstáculos oriundos dos universos diversificados e em constante mutação, típicos das dinâmicas fecundas do mundo contemporâneo. Estas performances abordaram questões ambientais, questões que discutem aspectos relativos à cibercultura, questões de gênero, questões relativas ao consumismo exacerbado, questões de cunho político no Brasil atual e questões calcadas no preconceito racial. As performances foram: Eu Tenho nome Próprio; Diane; Mãe, pai ou responsável. Ass: ; Sorria? Você está sendo Vigiado; reXistência; Aqui ou AliXo; Planalto; Jornada dupla, tripla, quádrupla; Joana Encaixotada. Os trabalhos preservam o tom anárquico da Performance Arte ao transgredir noções cristalizadas de atitudes socioculturais propostas pelos artistas. 
Ao longo do ano de 2016, foram realizados encontros semanais nos quais as performances foram elaboradas, apresentadas, discutidas e reelaboradas colaborativamente antes de irem a público. Cada performer escolheu seu argumento a partir de inquietações pessoais que, por sua vez, já faziam parte da vida de cada um, motivando-os a agir artisticamente pela via das experiências de vida e em campo. Durante o período em pesquisa de campo, cada artista registrou suas experiências em diários, assinalando não apenas os acontecimentos, mas também os objetos que participavam destes acontecimentos no entorno. Os afetamentos provenientes das escolhas consideradas relevantes por cada um atravessaram os corpos desde os argumentos defendidos por cada artista envolvido na criação; a abordagem estética; os elementos formais, como objetos, figurinos, sonoridades, entre outros; até as ações performativas. Posteriormente, cada momento em exposição para o grupo foi sendo lapidado em decorrência das interferências na experiência colaborativa. As nove propostas reformuladas foram reunidas e apresentadas na ExposiAção como parte integrante da programação do II Colóquio Internacional de Ética, Estética e Política do Centro de Artes e Letras da UFSM.

Um dos pontos abordados para discussão sobre a colaboratividade buscou repensar as hierarquias históricas nos atributos e status dos artistas em suas funções convencionais, de performer, diretor, ator, coreógrafo, bailarino, entre outras. Ao clarificar a discussão sobre hierarquias, pode-se perceber que esta atitude, consequentemente, gera e passa a atravessar questões relativas às autorias. Não se tratou de eliminar qualquer tipo de pensamento ou entendimento da noção de hierarquia sob o risco de recair no caos. Tratou-se de pensar sobre como estabelecer outras formas não autoritárias de hierarquias, ou seja, compreendê-las em sua funcionalidade, e não em seu componente de poder.

Em que plano residiria a eliminação (ou melhor, diluição) das hierarquias? $\mathrm{Na}$ liderança resultante da experiência ou de um saber pronunciado e acordado pelo grupo; no destaque e importância da ficha técnica de cada obra; nas influências sociais, culturais ou econômicas de determinados componentes do grupo? Como ela se estabelece? Pelo perfil profissional adequado das pessoas ou pelos retornos econômicos do investimento? Como os componentes dos grupos têm pensado a si mesmos neste contexto, como têm se autodenominado e porquê? Estas questões iluminam os cursos investigativos sobre as relações que se estabelecem nos grupos de artistas na contemporaneidade. Estas pesquisas não estão simplesmente interessadas em explorar e descrever o modus operandi dos grupos. Estas investigações refletem os interesses e necessidades técnico-expressivas-comunicativas dos seres humanos nas sociedades e comunidades atuais, ou seja, elas são frutos do modo de ser, pensar e agir contemporâneo.

Existem muitos grupos que se encaminham para trabalhos que, em maior ou menor grau, adotam esta atitude conjunta nas relações que estabelecem entre si. Cuidado, rigor, respeito e adequação a este novo modo de ser/estar no mundo contemporâneo, resguardado os interesses e necessidades individuais, parecem ser 
imprescindíveis nos trabalhos colaborativos. Por este motivo, já proliferam investigações voltadas para estas questões que se desdobram em possibilidades diversas de organização e planejamento. Atualmente, a criação em processos conjuntos assume um complexo e, às vezes, incompreensível ato de comunicação e interação entre individualidades dinamizadas e multifacetadas.

\section{Considerações transitórias}

A Performance Arte, ao subverter esteticamente ideias, valores e comportamentos enrijecidos e tidos como referência, estimula uma postura investigativa que tem alavancado as pesquisas, funcionando como suporte para construção dos corpos-arte multidisciplinares e colaborativos. O performer, quando em cena, assume uma atitude artística que depende da reelaboração de si enquanto arte, impulsionado pelos processos criadores aparentemente ilimitados da contemporaneidade.

A pesquisa de campo realizada como parte das ações do grupo de pesquisas tem sido referendada pela convivência com os focos investigativos, o que já estabelece as primeiras formas de colaboração. As experimentações acerca dos temas apontados transbordaram elementos simbólicos que remeteram às trocas de experiências em campo durante a investigação. Os procedimentos metodológicos oriundos do saber antropológico e seu olhar estranho, por sua vez, lançados a diferentes universos culturais, têm contribuído significativamente para as artes da cena. O estranhamento e a pesquisa de campo são ativadores extremamente férteis do processo orientado para a construção de outros saberes que diferem da própria Antropologia e transitam para o saber das artes performativas viabilizadas pelo corpo presencial e/ou virtual.

A experiência oriunda da convivência, por sua vez, foi transportada ao laboratório de criação, no qual foram experimentadas pelo atravessamento das sensibilidades poéticas dos outros artistas e estimuladas pelos objetos trazidos por eles dos campos investigados e registrados em diários. Portanto, as experimentações desenvolvidas individualmente e lançadas ao grupo em trocas sistemáticas sofreram, também, esta intervenção das experiências coletivizadas momentaneamente. Finalmente, as trocas que foram abertas à colaboração advinda, primeiramente, dos outros artistas pesquisadores do grupo se preparam para que depois sejam oferecidas à participação dos públicos de ambientes diversos. A diversidade tem sido reforçada pelo caráter itinerante do trabalho, que assumiu formas diferentes nos dois espaços-tempos em que se apresentou, mobilizando outros contatos e experiências imprevisíveis.

Aceitar a impossibilidade de prever resultados e aceitar o risco também são comportamentos fundamentais neste tipo de relação. A colaboração gera estruturas imprevistas, nas quais a potência do conhecimento prolifera exuberantemente. Os processos colaborativos tendem a começar e terminar em estruturas fragmentadas. Em primeiríssima instância, os trabalhos colaborativos são dirigidos pelo desejo de 
lidar com a diferença em liberdade. Seu imenso potencial social traz consigo uma forma de realização e experiência de criação ilimitadas.

O contexto dilatado e em constante expansão do mundo contemporâneo é amplificador destes modus operandi multidisciplinares que se reverberam, ainda, nas trocas entre os artistas contemporâneos e seus modos de operar. Os diversos modos de colaboração intercultural, artística e instantânea via contato com o público, por sua vez, vão gerando um campo ainda mais expandido na arte contemporânea, pois se permite arriscar em vários níveis de organização e funcionamento.

As possibilidades diversificadas oriundas deste processo escancaram estados de alienação e massificação aos quais os seres humanos encontram-se submetidos em meio ao bombardeio de informações acríticas que assolam os veículos de comunicação, congelando e padronizando o pensamento. As performances buscam oferecer um olhar sobre o ser humano para si e para o outro em contexto artístico. Esta experiência tem demonstrado a flexibilidade e a transdisciplinaridade que decorrem da abertura aos cruzamentos com saberes e de ações provenientes daqueles que se arriscam ao ato da criação.

Assim, este trabalho buscou contribuir para a reflexão sobre a atuação dos grupos de artistas multidisciplinares. Este contexto pode ser gerador de outros pensamentos sobre como os grupos se relacionam diante deste dinamismo sistêmico, como agem nesta mudança de paradigmas, como se dá esta alteração das práticas humanas, especialmente aqui, das práticas artísticas colaborativas, muitas delas se organizando como agrupamentos de curta duração, não exclusivos nem excludentes.

\section{Referências}

ABRAMOVIC, Marina. The Artist is Present. Direção de Matthew Akers. EUA, 2012.

BATTCOCK, Gregory. The Art of Performance. New York: E. P. Dutton, Inc., 1984.

BENJAMIN, Walter. A obra de arte na época de sua reprodutibilidade técnica. In: ADORNO, Theodor et al. Teoria da Cultura de Massa. São Paulo: Paz e Terra, 2000.

BIANCALANA, Gisela Reis. A Inserção do Conhecimento Artístico no Corpo Performativo. In:TAVARES, Enéias Farias; BIANCALANA, Gisela Reis; MAGNO, Mariane (Orgs.). Discursos do Corpo na Arte. Santa Maria, RS: Editora da UFSM, 2014.

BONDÍA, Jorge L. Notas sobre a experiência e o saber de experiência. Revista Brasileira de Educação, Rio de Janeiro, n.19, 2002.

COHEN, Renato. Performance como linguagem. São Paulo: Perspectiva, 2002. 
DAWSEY, John. Vitor Turner e a Antropologia da Experiência. Cadernos de Campo, São Paulo, n. 13, 2005.

DIDI-HUBERMANN, Georges. O que vemos, o que nos olha. São Paulo: Editora 34, 1998.

GALERIA, Luciana Brito. Back to Simplicity - Marina Abramovic. Catálogo. São Paulo, 2010.

GLUSBERG, Jorge. A arte da performance. Tradução Renato Cohen. São Paulo: Perspectiva, 1987.

GOLDBERG, Roselee. Performance Arte. Barcelona: Ediciones Destino, 2002.

LAPLANTINI, François. Aprender Antropologia. São Paulo: Editora Brasiliense, 1996.

MELIM, Regina. Performance nas Artes Visuais. Rio de Janeiro: Zahar, 2008.

PHELAN, Peggy. Ontologia da Performance: representação sem produção. Revista da Comunicação e Linguagem, Lisboa, Edição Cosmos, n. 24, 1997.

QUILICI, Cassiano. O Treinamento do Ator/performer e a "Inquietude de Si". V Congresso da ABRACE. Disponível em: http://www.portalabrace.org/vcongresso/textos/territorios. Acesso em: Nov. 2013.

RUSHAM, Martina. I want to work with you because I can speak for myself: The Potential of Postconsensual Collaboration in Choreographic Practice. In: Collaboration in Performance Practice. London: Palgrave Macmillan, 2015.

SCHECHNER, Richard. O que é Performance? O Percevejo, Rio de Janeiro, UNIRIO, ano 11, n.12, 2003.

SCHNEIDER, Florian. Collaboration-some thoughts concerning new ways of learning and working together. Frankfourt: Revolver Verlag, 2007.

TAYLOR, Diana. Performance. Buenos Aires: Asunto Impresso Ediciones, 2012. 